\title{
Levels of abscisic acid in anoxia- or ethylene-treated rice (Oryza sativa L.) seedlings
}

\author{
Tse-Min Lee*a, Huu-Sheng Lur ${ }^{b}$, Yuh-Jang Shieh", Chun Chu ${ }^{b}$ \\ "Institute of Botany, Academia Sinica. Nankang. Taiper. Tainam. Repuhlic of China \\ hopartmen of Agronomy. National Taivan Liniversity. Taipei. Tainam. Republic of China
}

(Received 16 April 1993; revision received 2 September 1993: accepted 8 September 1993)

\begin{abstract}
Changes of internal ABA levels in relation to anoxia- or ethylene-induced growth alterations were determined in etiolated rice (Oryza sativa L. cv. Taichung Native 1) seedlings. An inverse relationship between ABA levels and growth was observed at the early growth stages of rice seedlings. When rice seedlings were exposed to anoxia or $10 \mu 1 / 1$ ethylene. coleoptile elongation was enhanced while growth of roots and leaves was inhibited. In contrast, anoxiat or ethylene induced a decrease of ABA levels in coleoptiles but an increase in roots and leaves, especially after $48 \mathrm{~h}$ of treatment. In addition, the anoxia- or ethylene-enhanced coleoptile elongation was inhibited by ABA ranging from $10^{-7} \mathrm{M}$ to $10^{-4} \mathrm{M}$. Thus, results presented here indicate that ABA is an inhibitory modulator in the anoxia- or ethylene-induced morphological changes of etiolated rice seedlings.
\end{abstract}

Key words: Oryza sativa L; Anoxia: Ethylene: ABA: Morphological changes

\section{Introduction}

Rice is known to be one of the plants which can germinate and survive under anoxia or conditions of submergence [1-3]. However, these oxygenrestricted environments lead to morphological changes in rice seedlings such as stimulation of coleoptile elongation [4-7] and inhibition of root and leaf growth $[3,7]$. There is evidence that several

\footnotetext{
* Corresponding author.

Abhreviations: DW, dry weight: ELISA, enzyme-linked immunosorbent assay; FW, fresh weight: HPLC, high performance liquid chromatography; TBS. Tris buffer saline.
}

plant growth regulators including ethylene $[6,8-10]$, IAA $[5,6,11]$, and polyamines $[10,12,13]$ are involved in the morphological regulation of anoxia-grown rice seedlings.

It has been established that ABA is involved in the regulation of plant growth and development [14]. Stresses such as flooding [15-20] also induce ABA accumulation. However, levels of ABA in deepwater rice internodes show a significant decrease after submergence of plants [21]. It was suggested that the decrease of $\mathrm{ABA}$ levels is closely correlated with submergence-induced elongation of rice iniernodes. In the case of rice coleoptiles, a fluridone-induced decrease in ABA levels also 
showed a close correlation with fluridoneenhanced coleoptile elongation [21]. In addition, ABA application could inhibit rice coleoptile elongation under aerobic or anaerobic conditions [6]. These data suggest that ABA has an inhibitory role in the elongation of rice coleoptiles or internodes.

According to the above observations, we proposed that ABA might be one of the internal factors in the regulation of morphological alterations of rice seedlings grown under oxygen-restricted conditions or ethylene. Thus, experiments designed here were to examine changes of internal ABA levels in coleoptiles, leaves and roots of anoxia- or ethylene-treated rice seedlings, and also the relationships between ABA levels and growth of individual organs. Effects of $A B A$ on the anoxia- or ethylene-enhanced coleoptile elongation were also determined.

\section{Materials and methods}

Seeds of Indica type rice (Oryza sativa L. cv. Taichung Native 1) were sterilized with 5\% sodium hypochloride for $10 \mathrm{~min}$ and then washed several times with distilled $\mathrm{H}_{2} \mathrm{O}$, and germinated in Petri dishes at $30^{\circ} \mathrm{C}$ under darkness as previously reported [10]. For aerobic treatment, ten etiolated seedlings with a $4 \mathrm{~mm}$ shoot and $2 \mathrm{~mm}$ root were placed in a Petri dish $(8 \mathrm{~cm}$ width, $1 \mathrm{~cm}$ depth) containing $8 \mathrm{ml}$ distilled $\mathrm{H}_{2} \mathrm{O}$ such that seedlings were not submerged. For anaerobic treatment, ten seedlings were enclosed in a $30-\mathrm{ml}$ flask containing $5 \mathrm{ml}$ distilled $\mathrm{H}_{2} \mathrm{O}$, through which humidified nitrogen gas was passed at a flow rate of 10 $\mathrm{ml} / \mathrm{min}$. In response to ethylene treatment, ten seedlings were placed in a $25-\mathrm{ml}$ vial and $10 \mu \mathrm{l} / \mathrm{l}$ ethylene was passed through at a flow rate of 10 $\mathrm{ml} / \mathrm{min}$. Thus, in this study, ethylene was applied under air conditions.

Free ABA was extracted and determined according to Lee et al. [22]. Rice tissue (about $2 \mathrm{~g}, \mathrm{FW}$ ) was frozen in liquid $\mathrm{N}_{2}$ and lyophilized at $-50^{\circ} \mathrm{C}$. After lyophilization, samples (about $0.4 \mathrm{~g}, \mathrm{DW}$ ) were ground in liquid $\mathrm{N}_{2}$. A total $4 \mathrm{ml}$ of extraction solution $(80 \%$ methanol, $1 \%(\mathrm{v} / \mathrm{v})$ acetic acid, $100 \mathrm{mg} / \mathrm{l}$ of butylated hydroxytoluene) were added and shaken at $4^{\circ} \mathrm{C}$ for $36 \mathrm{~h}$ in darkness. In each sample, DL-cis,trans-[G- $\left.{ }^{3} \mathrm{H}\right]-\mathrm{ABA} \quad(166.5 \mathrm{~Bq}$,
0.1461 pmol) was added as an internal standard for estimating extraction efficiency during the extraction procedure. In these experiments, the ABA recovery ranged from $74-85 \%$. After $36 \mathrm{~h}$ extraction, extracts were filtered through Whatman No. 1 filter paper, and the filter papers were rinsed twice with $1 \mathrm{ml}$ extraction solution. The filtrate was evaporated completely in vacuo and resuspended first in $0.5 \mathrm{ml}$ of $100 \%$ methanol; 0.5 $\mathrm{ml}$ of $500 \mathrm{mM}\left(\mathrm{NH}_{4}\right)_{2} \mathrm{HPO}_{4}$ was subsequently added, and ammonium salts were allowed to form for about $10 \mathrm{~min}$ in an ice bath. The ammonium salt solution was passed through a PVP column ( 2 $\mathrm{g}$, DW polyvinylpoly pyrolidone in a $2.5-\mathrm{ml}$ plastic syringe) to remove pigments and phenolics and then ABA in the column was eluted out by applying $6 \mathrm{ml}$ distilled water. The PVP column-filtered solutions were combined and adjusted to $\mathrm{pH} 3.0$ with concentrated acetic acid. The acidified solution was eluted through a $\mathrm{C}_{18}$ cartridge (Waters, MA, USA) and $20 \%$ methanol ( $\mathrm{pH} 3.2)$ was then passed to remove polar compounds. ABA trapped in the $\mathrm{C}_{18}$ column was eluted with $4 \mathrm{ml}$ of $65 \%$ methanol ( $\mathrm{pH} 3.2$ ). After drying in vacuo, each sample was resuspended in $0.5 \mathrm{ml}$ of TBS solution (50 $\mathrm{mM}$ tris-hydroxymethylaminomethane $\mathrm{HCl}$, $10 \mathrm{mM} \mathrm{NaCl}, 1 \mathrm{mM} \mathrm{MgCl}, 15 \mathrm{mM} \mathrm{NaN}_{3}, \mathrm{pH}$ 7.5) and stored at $-20^{\circ} \mathrm{C}$ for further purification by HPLC fractionation. A Waters HPLC system (Waters, USA) equipped with a UV detector was employed in the purification of cis-ABA in the extract. A $5 \mu \mathrm{m} \mathrm{C}_{18}$ reverse column $(250 \mathrm{~mm} \times 4$ $\mathrm{mm}$, endcapped, E.Merck, FRG) was used. The cis-ABA of extracts was eluted with $40 \%$ methanol (HPLC grade, BDH, UK) containing $0.02 \%$ acetic acid within $24 \mathrm{~min}$ at a flow rate of $1 \mathrm{ml} / \mathrm{min}$. Excessive amounts of acetic acid (more than $0.05 \%)$ lowered the affinity between monoclonal antibody and ABA-4'-BSA or cis-ABA. cis-ABA was fractionated by fraction collector (Gilson, model EL-201, UK) and dried completely in vacuo. The dried samples were then lyophilized for $12 \mathrm{~h}$ in darkness to remove residual acetic acid. The lyophilized samples were resuspended in 475 $\mu \mathrm{l}$ of TBS solution and $25 \mu \mathrm{l}$ of $100 \%$ methanol and stored at $-20^{\circ} \mathrm{C}$ for ELISA analysis. By evaluating $\left[{ }^{3} \mathrm{H}\right] \mathrm{ABA}$ recovery, ABA loss was found to be less than $3.5 \%$ in these steps.

Levels of cis-ABA in samples were measured by 
indirect ELISA according to Walker-Simmons (1987) [23] and Norman et al. (1988) [24] with some modifications. In this experiment, ABA-4' BSA conjugate was used for the determination of free cis-(+)-ABA (Weiler, 1980) [25]. The conjugation of ABA to bovine serum albumin (BSA) at the C-4'position was performed according to Weiler (1980) [25]. The lyophilized ABA-4'-BSA conjugate was diluted to $35 \mu \mathrm{g} / \mathrm{ml}$, then each well of a flat bottom microtitration plate (Immuno 2 plate, Dynatech Laboratories, Inc., USA) was coated with $200 \mu$ l of diluted ABA-4'-BSA conjugate solution at $4^{\circ} \mathrm{C}$ for at least $24 \mathrm{~h}$ in darkness. The standards of ABA for calibration were prepared from cis-(+)-ABA (Sigma, USA) with ABA concentrations ranging from $0.01-10 \mathrm{pmol}$ in $100 \mu \mathrm{l}$ TBS solution. Standard curves were linearized by plotting the logit transformation of absorbance data against log of standard ABA concentration. In our experiments, a linear relationship was found to apply within the range of 0.01-10 pmol. Samples were diluted to appropriate concentrations in linear ranges for the ELISA assay. The ABA-4'-BSA conjugate was discarded and plates were washed with $200 \mu \mathrm{l}$ TBS solution containing $0.05 \%$ Tween 20 and $500 \mathrm{mg} / \mathrm{l} \mathrm{BSA}$ $(w / v)$. Then $200 \mu \mathrm{l}$ of TBS solution containing $0.05 \%$ Tween 20 were added to each well and discarded after standing for $5 \mathrm{~min}$. The mixture of $100 \mu \mathrm{l}$ standards or samples and $100 \mu \mathrm{l}$ diluted monoclonal antibody ( $2 \mathrm{ng} / \mathrm{ml}$ TBS solution) was added to the wells and then incubated at $30^{\circ} \mathrm{C}$ under darkness for $6 \mathrm{~h}$. Wells were subsequently washed three times with TBS solution containing $0.05 \%$ Tween 20 and $500 \mathrm{mg} / 1 \mathrm{BSA}$, and $200 \mu \mathrm{l}$ of diluted rabbit antimouse antiserum alkaline phosphatase conjugate (1:1000 dilution with TBS solution containing $40 \mathrm{~g} / 1$ polyethylenglycol 6000 , purchased from Sigma, USA) were added. After incubation at $30^{\circ} \mathrm{C}$ under darkness for $3 \mathrm{~h}$, wells were washed three times with TBS solution containing $0.05 \%$ Tween 20 . Two hundred $\mu \mathrm{l} p$ nitrophenyl phosphate disodium salt $(1 \mathrm{~g} / 1$ in 50 $\mathrm{mM}$ bicarbonate buffer, $\mathrm{pH}$ 9.6) were added and incubated at $37^{\circ} \mathrm{C}$ for $50 \mathrm{~min}$. The reaction was stopped by adding $50 \mu \mathrm{l}$ of $5 \mathrm{~N} \mathrm{KOH}$. The absorbance at $405 \mathrm{~nm}$ was measured with an EIA reader (model EL308, BIO-TEK, USA). Standards and samples were replicated at least three times in the same ELISA plate. ABA concentrations in samples were calculated from the regression curve of standard ABA in each plate. ABA determined by ELISA was validated by GC-MS. The ABA concentration of each sample was the average of three replicates.

In this experiment, DL-cis,trans-[G- $\left.{ }^{3} \mathrm{H}\right] \mathrm{ABA}$ (1.91 $\mathrm{TBq} / \mathrm{mmol}$ ) was obtained from Amersham (Buckinghamshire, England, UK). Monoclonal antibody for (S)-ABA was purchased from Idetek Inc. in USA. Other chemicals were obtained from Sigma or Merck Inc.

\section{Results}

3.1. Effects of anoxia on length, fresh weight and ABA levels of coleoptiles

Etiolated seedlings with 4-mm long coleoptiles were used in all experiments. As shown in Fig. 1, the coleoptile elongation was enhanced by anoxia and could reach up to $33.2 \mathrm{~mm}$ after $96 \mathrm{~h}$ treatment. Coleoptiles grown under aerobic conditions only elongated to $12.4 \mathrm{~mm}$ even after $96 \mathrm{~h}$ (Fig. 1). The fresh weight of anaerobically grown coleoptiles was also higher than that of aerobically grown ones (Fig. 1).

Changes of internal ABA levels in coleoptiles of

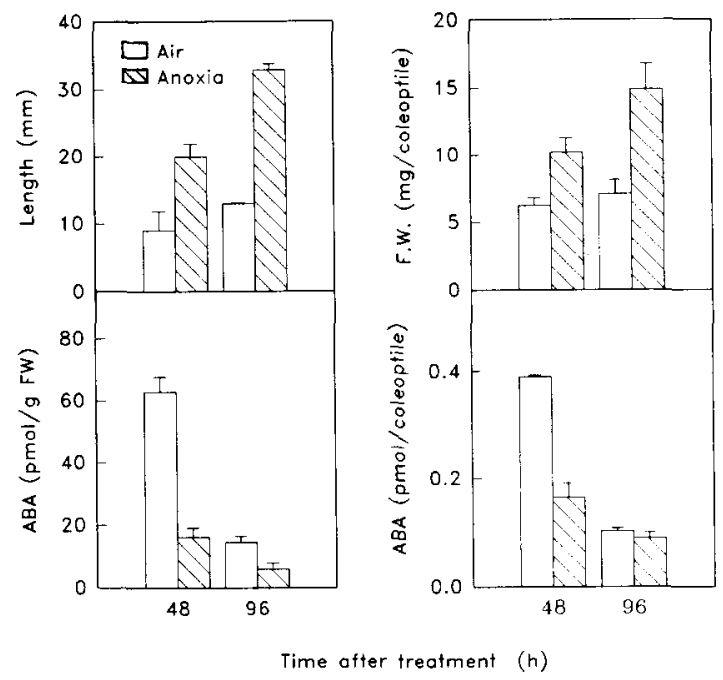

Fig. 1. Length, fresh weight (FW) and ABA levels in rice coleoptiles grown in air $(\square)$ or under anoxia $(\mathbb{Z})$. Bars indicate standard error. 
anaerobically grown rice seedlings are shown in Fig. 1. As compared with air controls, ABA levels were significantly reduced by anoxia. However, if expressed on a per coleoptile unit, the absloute ABA amount in anaerobically grown coleoptiles was almost the same as that in aerobically grown ones after $96 \mathrm{~h}$ treatment.

\subsection{Effects of anoxia on length, fresh weight and} $A B A$ levels of leaves and roots

Changes of growth and ABA levels in leaves in response to anaerobic conditions are presented in Fig. 2. When transferred to anaerobic conditions, leaf elongation as well as its fresh weight increase were inhibited. If expressed on a concentration basis (i.e. pmol/g FW), ABA levels increased under anaerobic conditions and reached a level of 5- and 7 -fold of that in air controls after $48 \mathrm{~h}$ and $96 \mathrm{~h}$, respectively. In contrast, if based on a per leaf unit, the absolute ABA amount in each leaf of the seedling leaves was lower under anaerobic conditions than under aerobic conditions.

As shown in Fig. 3, aerobically grown roots elongated rapidly as growth periods increased but elongation of anaerobically grown roots was seriously inhibited under anaerobic conditions.

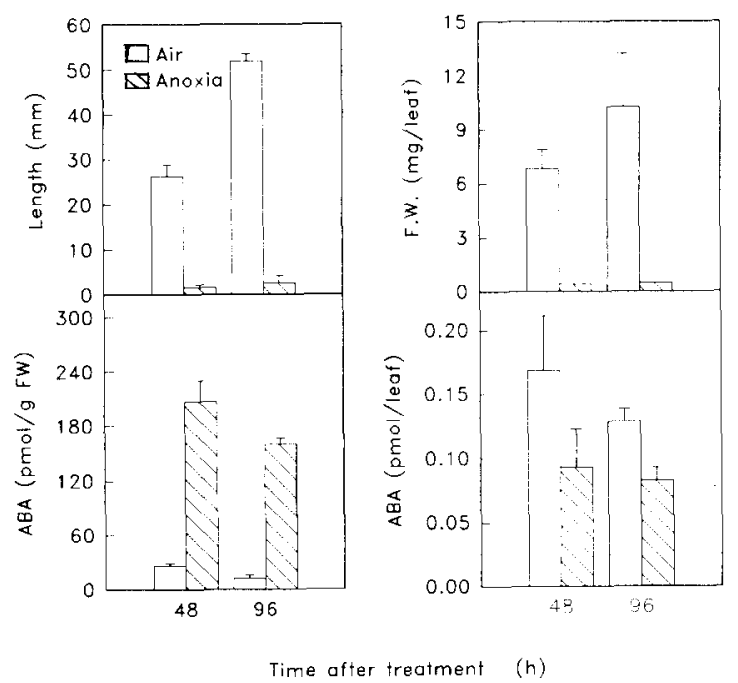

Fig. 2. Length, fresh weight ( $F W$ ) and $A B A$ levels in rice leaves grown in air $(\square)$ or under anoxia $(\mathbb{D})$. Bars indicate standard error.

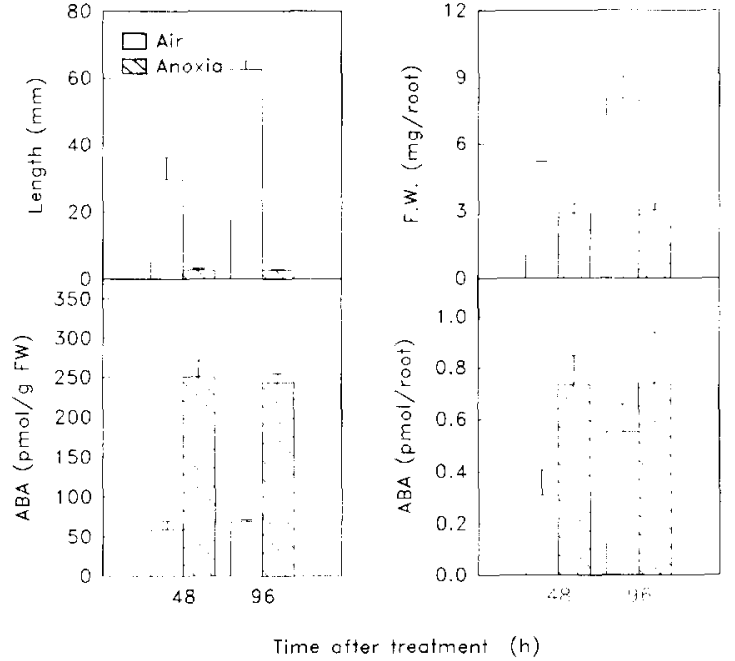

Fig. 3. Length, fresh weight (FW) and $A B A$ levels in rice leaves grown in air $(\square)$ or under anoxia $(\mathbb{D})$. Bars indicate standard error.

Similarly, as compared with aerobic controls, increase of fresh weight in roots was also inhibited by anoxia treatment (Fig. 3). Fig. 3 showed that ABA levels of anaerobically grown roots were higher than those of aerobic controls (Fig. 3).

\subsection{Effects of ethylene on seedling growth and $A B A$ levels}

Responses of growth of etiolated rice seedlings to $10 \mu \mathrm{l} / 1$ ethylene are shown in Fig. 4 . After exposure to ethylene for $48 \mathrm{~h}$, coleoptile elongation was enhanced but growth of leaves or roots was inhibited. A similar response was also observed in changes of fresh weight. Ethylene resulted in an increase of fresh weight in coleoptiles but an inhibition in leaves and roots. In coleoptiles, ABA levels showed a decrease after $48 \mathrm{~h}$ of ethylene treatment (Fig. 4). In contrast, an increase of ABA levels was found in roots and leaves after exposure to ethylene (Fig. 4). However, if based on a per leaf unit, the absolute ABA amount in each seedling's leaves was almost the same between air and ethylene treatment (Fig. 4).

\subsection{Effects of $A B A$ on anoxia- or ethylene- enhanced coleoptile elongation}

As shown in the above results, it seems that 


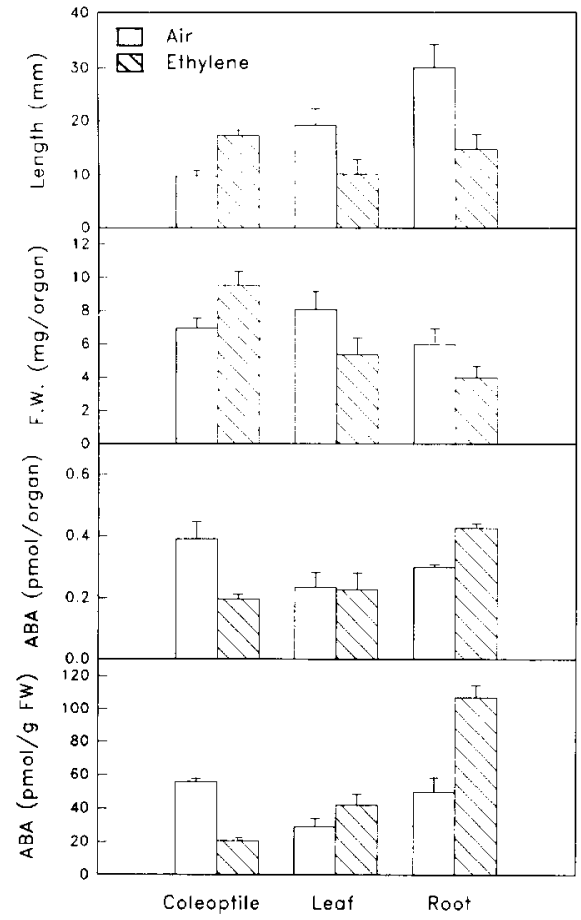

Fig. 4. Length, fresh weight (FW) and ABA levels in organs of rice seedlings after exposure to ethylene $(10 \mu \mathrm{l})$ for $48 \mathrm{~h}$. (D) Air; $(\mathbb{Q})$ ethylene. Bars indicate standard error.

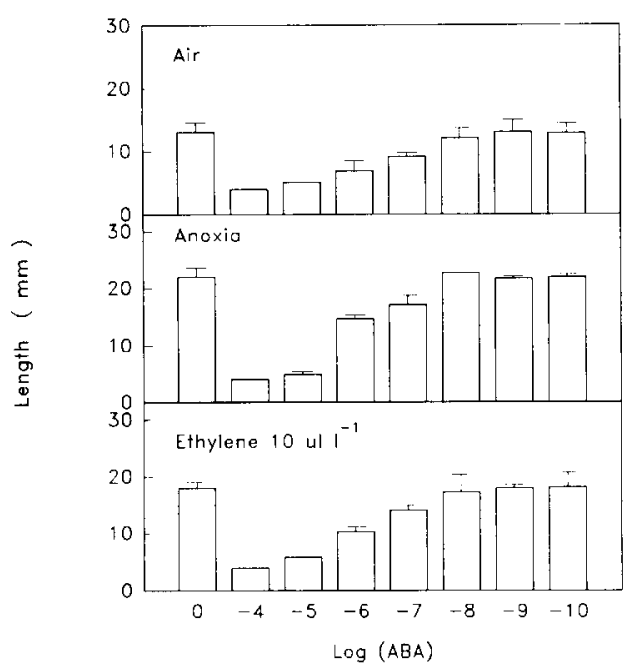

Fig. 5. Effects of various ABA concentrations on coleoptile length of rice seedlings grown under air, anoxia or ethylene conditions. ABA was treated together with ethylene or anoxia. Coleoptile length was determined after $48 \mathrm{~h}$ treatment. Bars indicate standard error. internal ABA levels are reversely related with elongation of anoxia- or ethylene-treated coleoptiles. If ABA does play an internal factor as an inhibitory factor in the regulation of coleoptile elongation under anoxia or ethylene treatment, ABA application should inhibit the anoxia- or ethylene-induced coleoptile elongation. Here, changes of coleoptile length in response to various levels of ABA were examined under air, anoxia or ethylene conditions. As shown in Fig. 5, ABA used in concentrations from $10^{-7} \mathrm{M}$ to $10^{-4} \mathrm{M}$ inhibited elongation of aerobically grown coleoptiles. Similarly, elongation of anoxia- or ethylenetreated coleoptiles was found to be inhibited by ABA (Fig. 5). Although the degree of ABAinhibited coleoptile elongation increased as ABA concentration increased, ABA ranges which could inhibit coleoptile elongation were all the same among different treatments (Fig. 5).

\section{Discussion}

The results presented here show that $\mathrm{ABA}$ may have a negative role in the regulation of anoxiaand ethylene-induced morphological changes of etiolated rice seedlings at the early growth periods. After exposure to anoxia or ethylene for $48 \mathrm{~h}$, an inverse relationship between internal ABA levels and growth was observed in coleoptiles, roots as well as leaves of rice seedlings. In addition, the anoxia- or ethylene-enhanced elongation of coleoptiles was also inhibited by ABA ranging from $10^{-7} \mathrm{M}$ to $10^{-4} \mathrm{M}$. ABA has been generally accepted as an inhibitor for plant growth [14]. Recently, it has been suggested that ABA may play an inhibitory role in the elongation of aerobicgrown rice coleoptiles [21]. In the case of deepwater rice internodes, the ethylene-induced decrease of ABA levels was also found to have a close association with the ethylene-induced elongation [21]. However, current studies showed that, in response to prolonged anoxia treatment (i.e., after $96 \mathrm{~h}$ of treatment), ABA levels in coleoptiles and roots were almost the same between aerobic and anaerobic conditions. Therefore, at the later growth stages of etiolated rice seedlings, ABA may not be an essential factor for anoxia- 
induced changes in growth of coleoptiles and roots.

It is surprising that, if expressed on a per leaf unit, the absolute ABA amount in leaves was higher in anoxia or ethylene conditions than in aerobic conditions. This was a contrast with the concentration results (i.e., a per gram fresh weight unit). It is apparently caused by a remarkable increase of fresh weight in aerobically grown leaves and an inhibition of fresh weight increase in anaerobically grown or ethylene-treated ones. Although it is possible that factors other than ABA might be also involved in the anoxia- or ethylene-induced inhibition of growth of rice leaves, current results from ABA concentration in leaves indicate that, to some extent, $A B A$ still shows an inhibitory role in the regulation of leaf growth under anaerobic or ethylene conditions.

In consideration of the inhibition of ethylene biosynthesis by complete oxygen-free conditions [28], ethylene could not be a factor in anoxiainduced $\mathrm{ABA}$ decrease in coleoptiles. Besides, it has been also demonstrated that ethylene had little effect on anoxia-enhanced coleoptile elongation [6].

In addition, mechanisms in the regulation of different responses of ABA levels in coleoptiles, roots and leaves under conditions of anoxia and ethylene are not fully understood. Since anoxia or ethylene did not alter levels of conjugated $A B A$ in each organ (data not shown), ABA levels were therefore not regulated by changes in conjugation processes. Alternatively, a similar aspect reported by Dashek et al. [29] in barley aleurone layers, ABA metabolism might be a tissue-specific response among organs of rice seedlings grown under anoxia or ethylene treatment. Furthermore, although ABA metabolic enzymes are not completely understood, activity of the mixed-function oxygenase involved in the conversion of $\mathrm{ABA}$ to $6^{\prime}$-hydroxymethyl ABA [30] may be enhanced in coleoptiles or depressed in roots under anaerobic conditions. However, further studies such as feeding of $\left[{ }^{3} \mathrm{H}\right] \mathrm{ABA}$ and determination of its metabolites will be required to prove the above proposals. It is also not clear whether ABA metabolism is similar between anoxia and ethylene treatment.
Because of an involvement of multiple factors in the complex control of plant growth, ABA alone can not explain the whole picture of rice seedling growth in response to anoxia or ethylene. As reported by Horton [6], kinetin also showed an inhibition effect on the coleoptile elongation of anoxia-treated rice seedlings. Thus, except ABA, kinetin may also be an inhibitor for rice coleoptile elongation. Alternatively, in addition to inhibitory factors like ABA and kinetin, enhancers may be also involved in anoxia or ethylene-induced changes of rice seedling growth. For the elongation of rice coleoptiles, although IAA has been established to be a promoter, the internal IAA levels in anaerobically grown coleoptiles have been recently reported to be the same as those in aerobically grown ones [26]. In addition to IAA, putrescine may be also a candidate. Based on experiments from the inhibition of coleoptile elongation by putrescine biosynthetic inhibitor, DFMA ( $\alpha$-difluoromethylarginine), and also the recovery of the effect of DFMA by putrescine, it has been proved that putrescine is an essential internal factor for rice coleoptile elongation in anaerobic conditions [12,13]. In addition, putrescine has also been suggested to play a role in the ethylene-enhanced coleoptile elongation of rice seedlings [10]. It is therefore interesting to know the relationship between $\mathrm{ABA}$ and putrescine in rice coleoptiles grown under anoxia or ethylene treatment. Now, the interactions between ABA and putrescine is being examined.

In summary, ABA is intimately associated with enhancement of coleoptile elongation and inhibition of root and leaf growth under conditions of anoxia or ethylene. As it is generally accepted, evidence presented here shows that ABA is a common growth inhibitor for rice seedlings in response to anaerobic or ethylene treatment.

\section{Acknowledgements}

This work was supported in part by the Council of Agriculture and National Science Council, Executive Yuan, Republic of China (R.O.C.). The author, Tse-Min Lee, who is a post-doctoral fellow in the Institute of Botany, Academia Sinica, Republic of China (R.O.C.), wishes to thank the 
National Science Council, Executive Yuan, Republic of China (R.O.C.), for financial support.

\section{References}

1 L. Tayor, Influence of oxygen tension on respiration fermentation and growth in wheat and rice. Am. J. Bot., 29 (1942) 721-738.

2 A. Alpi and $\mathrm{H}$. Beevers, Effects of $\mathrm{O}_{2}$ concentration on rice seedlings. Plant Physiol., 71 (1983) 30-34.

3 F.T. Turner, C.C. Chen, G.N. McCauley, Morphological development of rice seedlings in water of controlled oxygen levels. Agron. J., 73 (1981) 566-570.

4 H.A. Kordan, Coleoptile emergence in rice seedlings in different oxygen environments. Ann. Bot., 41 (1977) 963-969.

5 N. Yamada, Auxin relationships of the rice coleoptile. Plant Physiol., 29 (1954) 92-96.

6 R.F. Horton, The effect of ethylene and other regulators on coleoptile growth of rice under anoxia. Plant Sci., 79 (1991) 57-62.

7 I. Raskin and H. Kende, Regulation of growth in rice seedlings. J. Plant Growth Regul., 2 (1983) 193-203.

8 H.S. Ku, H. Suge, L. Rappaport and H.K. Pratt, Stimulation of rice coleoptile growth by ethylene. Planta., 90 (1970) 333-339.

9 B.J. Atwell, 1. Waters and H. Greenway. The effect of oxygen and turbulence on elongation of coleoptiles of submergence tolerant and intolerant rice cultivars. J. Exp. Bot., 33 (1982) 1030-1040.

10 T.M. Lee and C. Chu, Ethylene-induced polyamine accumulation in rice (Oryza sativa L.) coleoptiles. Plant Physiol., 100 (1992) 238-245.

11 M.B. Jackson and D.M.E. Pearce, Hormones and morphological adaptation to aeration stress in rice, in: M.B. Jackson, D.D. Davies and H. Lambers (Eds.), Plant Life under Oxygen Deprivation, SPB Academic Publishing, The Hague, Netherlands, 1991, pp. 47-67.

12 R. Reggiani, A. Hochkoeppler and A. Bertani, Polyamines and anaerobic elongation of rice coleoptile. Plant Cell Physiol., 30 (1989) 893-898.

13 R. Reggiani, A. Hochkoeppler and A. Bertani, Polyamines in rice seedlings under oxygen-deficit stress. Plant Physiol., 91 (1989) 1197-1201.

14 J.A.D. Zeevaart and R.A. Creelman, Metabolism and physiology of abscisic acid. Ann. Rev. Plant Physiol. Plant Mol. Biol., 39 (1988) 439-473.

15 S.T.C. Wright and R.W.P. Hiron, The accumulation of abscisic acid in plants during wilting and under other stress conditions, in: D.J. Carr (Ed.), Plant Growth Substance, Springer-Verlag, Berlin, 1970, pp. 291-298.

16 B. Shaybany and G.C. Martin, Abscisic acid identification and its quantitation in leaves of Juglans seedlings during waterlogging. J. Am. Soc. Hort. Sci., 102 (1977) 300-302.

17 S. Sivakumaran and M.A. Hall, Effects of age and water stress on endogenous levels of plant growth regulators in Euphorbia lathyrus. J. Exp. Bot., 29 (1978) 195-205.

18 W. Wadman-Van Schravendijk and O.M. Van Andel, Interdependence of growth, water relations and abscisic acid level in Phaseolus vulgaris during waterlogging. Physiol. Plant., 63 (1985) 215-220.

19 J. Zhang and W.J. Davies, Chemical and hydraulic influences on the stomata of flooded plants. J. Exp. Bot., 37 (1986) 1479-1491.

20 J. Zhang and W.J. Davies, ABA in roots and leaves of flooded pea plants. J. Exp. Bot., 38 (1987) 649-659.

21 S. Hoffmann-Benning and $\mathrm{H}$. Kende, On the role of abscisic acid and gibberellin in the regulation of growth in rice. Plant Physiol., 99 (1992) 1156-1161.

22 T.M. Lee, H.S. Lur and C. Chu, Role of abscisic acid in chilling tolerance of rice (Oryza sativa L.) seedlings $\mathbf{I}$. endogenous abscisic acid levels. Plant Cell Environ., 16 (1993) 481-490.

23 M. Walker-Simmons, ABA levels and sensitivity in developing wheat embryos of sprouting resistant and susceptible cultivars. Plant Physiol., 84 (1987) 61-66.

24 S.M. Norman, S.M. Poling and V.P. Maier, An indirect enzyme-linked immunosorbent assay for (+)-abscisic acid in Citrus, Ricinus, and Xanthium leaves. J. Agric. Food Chem., 36 (1988) 225-231.

25 E.W. Weiler, Radioimmunoassays for the diferential and direct analysis of free and conjugated abscisic acid in plant extracts. Planta, 148 (1980) 262-272.

26 T. Hoson, Y. Masuda and P.E. Pilet, Auxin content in air and water grown rice coleoptiles. J. Plant Physiol., 139 (1992) 685-689.

$27 \mathrm{~K}$. Ishizawa and Y. Esashi, Gaseous factors involved in the enhanced elongation of rice coleoptiles under water. Plant Cell Environ., 7 (1984) 239-245.

28 S.F. Yang and N.E. Hoffman, Ethylene biosynthesis and its regulation in higher plants. Ann. Rev. Plant Physiol., 35 (1984) 155-189.

29 W.V. Dashek, B.N. Singh and D.C. Walton, Abscisic acid localization and metabolism in barley aleurone layers. Plant Physiol., 64 (1979) 43-48.

30 D.F. Gillard and D.C. Walton. Abscisic acid metabolism by a cell-free preparation from Echinocystis lobata liquid endosperm. Plant Physiol., 58 (1976) 790-795. 